\title{
Changes in Muscle Tone Are Regulated by D1 and D2 Dopamine Receptors in the Ventral Striatum and D1 Receptors in the Substantia Nigra
}

Kim M. Hemsley, B.App.Sci., Ph.D., and Ann D. Crocker, B.Sc.(Hons), Ph.D.

Muscle rigidity associated with antipsychotic drug treatment is believed to result from reduced striatal dopamine neurotransmission. In the current study the regulatory roles of dopamine $D 1$ and $D 2$ receptor subfamilies in the dorsal (DSTR) and ventral striatum (VSTR) and substantia nigra (SN) were investigated on muscle tone, assessed as increases in tonic electromyographic (EMG) activity. Rats were injected with the irreversible D1/D2 antagonist $N$-ethoxycarbonyl-2ethoxy,-1,2-dihydroquinoline (EEDQ), the reversible D1 antagonist SCH23390, or D2 antagonist sulpiride.

Increased EMG activity was observed following injection of
EEDQ and SCH23390 into the SN or VSTR, and sulpiride into the VSTR. Mapping, using quantitative autoradiographic analysis of dopamine receptor occupancy after striatal injections, showed D1 and D2 receptors in discrete ventral sites were associated with EMG increases. Overall the results support roles for dopamine D1and D2 receptors in the ventral striatum, and $D 1$ receptors in the substantia nigra, in the regulation of muscle tone.

[Neuropsychopharmacology 25:514-526, 2001]

(C) 2001 American College of Neuropsychopharmacology.

Published by Elsevier Science Inc.
KEY WORDS: Muscle Rigidity; Extrapyramidal Side Effects; Dopamine Receptors; Antipsychotic Drugs; Ventral Striatum; Substantia Nigra

The use of antipsychotic drugs to treat the symptoms of schizophrenia can be associated with extrapyramidal side effects, which resemble the symptoms of Parkin-

From the Department of Clinical Pharmacology and Centre for Neuroscience, Flinders University of South Australia, Bedford Park, Australia.

Address correspondence to: Professor Ann Crocker, Flinders University of South Australia, Centre for Neuroscience, Department of Clinical Pharmacology, Bedford Park, SA 5042, Australia. Tel: +61-8-8204 5320; Fax: +61-8-204-5114; E-mail: Ann.Crocker@Flinders. edu.au

Received June 26, 2000; revised February 13, 2001; accepted February 26, 2001.

Online publication: 2/28/01 at www.acnp.org/citations/Npp02280185. son's disease and include increased muscle rigidity in up to $40 \%$ of patients (Baldessarini and Tarsy 1980). Further, it has been estimated that up to $30 \%$ of patients stop taking their medication because of these motor side effects (Hoge et al. 1990). It is not fully understood why antipsychotic drugs, all antagonists at the dopamine D2 receptor (Creese et al. 1976; Seeman et al. 1976; Peroutka and Snyder 1980) produce motor side effects, although there is some early experimental evidence supporting the view that antagonism of D2 receptors in the striatum is important (Chiodo and Bunney 1983; Creese 1983). Findings from studies in humans using positron emission tomography (PET) have led to the concept that a "threshold" of D2 antagonism by antipsychotic drugs of approximately $70 \%$, exists in the striatum, above which patients experience motor side effects (Farde et al. 1992; Nordstrom et al. 1995). Additional support for the striatal D2 threshold hypothesis has 
been provided by studies using experimental animals (Leysen et al. 1993; Ogren et al. 1994; Alcock and Crocker 1999; Hemsley and Crocker 1999a) and other imaging techniques in humans (Scherer et al. 1994). Further, it has been reported that clozapine, which does not produce motor side effects in humans or animals (Claghorn et al. 1987; Casey 1989), occupies sub-threshold levels of D2 receptors in the striatum (Farde et al. 1992; Hemsley and Crocker 1999a) and substantia nigra (Hemsley and Crocker 1999a).

The role of dopamine D1 receptors in the production of motor side effects is unclear, and no relationship to D1 receptor occupancy was shown in PET studies (Farde et al. 1992). However, there is evidence that antagonism of D1 receptors may result in motor side effects (Karlsson et al. 1995; Sedvall et al. 1995) and elicit such motor behaviors as catalepsy in rats (Ogren and Fuxe 1988). As many commonly used antipsychotic drugs, such as chlorpromazine, fluphenazine, and clozapine, are also potent dopamine D1 antagonists (Hacksell et al. 1995), it would be useful to understand the contribution that antagonism of the D1 receptor subfamily makes to the production of muscle rigidity.

Experimental research investigating the mechanisms underlying the motor side effects associated with the use of antipsychotic drugs has been handicapped by the lack of a relevant, objective, and quantifiable endpoint of extrapyramidal side effects in humans. In the current study we have assessed increases in muscle tone, which underlie muscle rigidity, as changes in tonic electromyographic (EMG) activity of the antagonistic muscles of the hindlimb of unrestrained, conscious rats. We have reported previously that significant increases in tonic EMG activity, sustained for at least $2 \mathrm{hr}$, are associated with subjective ratings of muscle rigidity (such as palpation), and occur following either lesions of the nigrostriatal dopamine pathway (Double and Crocker 1993) or irreversible dopamine receptor inactivation using EEDQ (Hemsley and Crocker 1998). Using the EMG technique we have extended the findings from PET studies in humans (Farde et al. 1992; Nordstrom et al. 1995) by showing that a number of antipsychotic drugs dose-dependently increase EMG activity and significant increases in EMG activity were associated with approximately 70\% D2 receptor occupancy in both the striatum and the substantia nigra. However, clozapine failed to increase EMG activity at doses up to $40 \mathrm{mg} / \mathrm{kg}$ (Hemsley and Crocker 1999a).

The aim of the current study was to elucidate whether both dopamine D1 and D2 receptor subfamilies are involved in the regulation of muscle tone and to identify their location. We investigated the effects on EMG activity of injecting reversible dopamine antagonists into three sites within the basal ganglia: the substantia nigra (SN), the ventral (VSTR), and the dorsal (DSTR) striatum. The choice of the nigral site was deter- mined by our earlier findings supporting a role for nigral dopamine receptors in the regulation of EMG activity (Double and Crocker 1995; Crocker 1997; Hemsley and Crocker 1998) and their involvement in motor behavior (LaHoste and Marshall 1990; Yurek and Hipkens 1994; Lee, Double and Crocker 1995). The striatal sites were selected on the basis that the dorsal striatum receives topographical inputs from the motor cortex controlling the hindlimb, and there is considerable evidence to suggest a crucial role for this dorsal region in the production of normal movement (Webster 1961; Wise and Jones 1977: Cospito and Kultas-Ilinsky 1981; Kelley et al. 1982; Donoghue and Herkenham 1986; Cohen and Hallett 1988; Carelli and West 1991). The ventral site was chosen because we have previously localized dopamine receptors in the ventral striatum that are involved in the appearance of dopamine agonist elicited behaviors (Cameron and Crocker 1989). In addition a number of other reports suggest a possible integratory role for dopamine receptors in the ventral region of the striatum (Turski et al. 1984; Arnt 1985; Ossowska et al. 1990; Crocker and Cameron 1992; Wardas et al. 1995; Alcock and Crocker 1999).

Two experimental approaches were used. Initial experiments were designed to determine the role of striatal dopamine receptors in the regulation of EMG activity by investigating the effects of irreversible inactivation of dopamine receptors following injection of EEDQ into dorsal or ventral striatal sites. We have previously reported findings using this approach that confirmed nigral dopamine receptors are involved in the regulation of muscle tone (Double and Crocker 1995; Hemsley and Crocker 1998), but unexpectedly found no evidence for involvement of striatal dopamine receptors (Double and Crocker 1995). A recent re-examination of these autoradiographs showed that most of the striatal EEDQ injections occupied predominantly dorsal sites, prompting the current investigation of both dorsal and ventral striatal sites.

The purpose of the second series of experiments was to determine the involvement of D1 and D2 receptors in the striatum and substantia nigra in the regulation of EMG activity by investigating the effects of injections of $\mathrm{SCH} 23390$ or sulpiride, selective D1 and D2 antagonists, respectively, into the three sites.

In both sets of experiments, D1 and D2 dopamine receptor occupancy was assessed using ex vivo quantitative autoradiography to identify the site of injection and clarify which dopamine receptor subfamily was involved in mediating EMG increases. We have previously used this mapping technique successfully to localize the dopamine receptors involved in apomorphine-induced stereotyped head-down sniffing (Cameron and Crocker 1989). Parts of the current study have been published previously in the form of an abstract (Hemsley and Crocker 1999b). 


\section{MATERIALS AND METHODS}

\section{Animals and Drugs}

Male Sprague-Dawley rats (250-350g) supplied by the Animal House of the Flinders Medical Centre, were housed in groups of five, maintained under conditions of constant temperature and humidity on a 12-hour light/dark cycle, and given free access to food and water. All experiments were carried out in accordance with the guidelines of the Australian National Health and Medical Research Council (NHMRC), and were approved by the Flinders University of South Australia Animal Ethics Committee.

All efforts were made to reduce animal pain or suffering and animals were closely monitored for signs of distress. Any animal observed to be in pain or distress that could not be alleviated, was administered a fatal dose of sodium pentobarbital. The minimum number of animals to provide statistically meaningful data was used.

Rats were anaesthetized with sodium pentobarbital (45 mg/ $\mathrm{kg}$ ) and placed in a stereotaxic frame; the head was fixed in a horizontal position. An opening in the skin above the skull was made, and resected laterally. The membranes covering the skull were cleared and burr holes (bilateral) were made at positions determined with the aid of a stereotaxic atlas (Paxinos and Watson 1986) to be above the sites of interest. Injection co-ordinates (in $\mathrm{mm}$ ) were; substantia nigra P-5.2, L2.4, V-7.8; dorsal striatum A 1.0, L 3.4, V-4.4; ventral striatum A 1.3, L 3.2, V-6.6. The injection system comprised 27G dental needles (0.4 mm diameter, Halas Dental, Adelaide, Australia) inserted into the end of clear plastic tubing (Critchley Electrical, Silverwater, New South Wales, Australia; I.D. 0.35 mm, O.D. $1.05 \mathrm{~mm}$ ), which were secured in the stereotaxic apparatus and connected to water filled $5 \mu$ l Hamilton syringes on a motor driven pump (Sage Instruments, Thermo Orion, Beverly, MA, USA). After being filled with drug or vehicle, the needles were slowly lowered vertically into the brain and bilateral injections made over $3 \mathrm{~min}$.

N-ethoxycarbonyl-2-ethoxy,-1,2-dihydroquinoline (EEDQ) (1 M in DMSO: Sigma, Sydney, Australia), sulpiride (30 nM in saline, Sigma), and SCH23390 (20 nM in saline, RBI) were administered in volumes of $0.2 \mu \mathrm{l}$ or $0.5 \mu \mathrm{l}$. The concentrations of SCH23390 and sulpiride injected were based on those reported in the literature (Koshikawa et al. 1989; Ossowska et al. 1990). The needles were left for a further $3 \mathrm{~min}$ before being slowly withdrawn and checked for blockages. The burr holes were sealed with stainless steel screws (Unisol Optical, Australia).

Where rats received an injection of EEDQ following pre-protection of dopamine receptors, SCH23390 (1.7 $\mu \mathrm{mol})$ and raclopride ( $75 \mu \mathrm{mol}$, gift of Astra, Sodertalje, Sweden) $(1 \mathrm{ml} / \mathrm{kg}$; s.c.) were co-administered $1 \mathrm{hr}$ before central injection of EEDQ.

\section{EMG Measurements}

While the animal was under anesthesia, electrodes to record tonic EMG activity were implanted into the antagonistic muscles of the right hindlimb as described previously (Double and Crocker 1993). Briefly, two pairs of stainless steel electrodes (Cooner Wire, Chatsworth, CA, USA) were introduced via the opening in the skin over the skull and passed subcutaneously down the body of the animal. The bared ends of one pair of wires were implanted into the gastrocnemius and the other into the anterior tibialis muscle, approximately 1 $\mathrm{cm}$ apart in the longitudinal plane of the muscle. The end of a fifth wire was bared and laid on the surface of the tibialis muscle to act as an earth. The other ends of the wires were connected to a five-pin male connector (Mayer-Krieg, Adelaide, Australia) that was cemented to screws on the skull of the animal.

Animals were connected via a headpiece containing an amplifier to a Grass polygraph (Model 7D), and the raw EMG signal was amplified, rectified, filtered (10 $\mathrm{Hz}-10 \mathrm{kHz}$ ) and integrated over $10 \mathrm{~s}$ periods. The resultant signal was recorded at $10 \mathrm{~Hz}$ for $20 \mathrm{~min}$ periods on a computerized recording system (CODAS, Dataq, Akron, Ohio, USA). EMG is expressed as mean integrated tonic EMG activity (mV/10 s \pm SEM) for a 20 min recording period at the beginning of each hour post-injection. EMG activity was recorded from both muscles for up to $5 \mathrm{hr}$ post-injection, and in one group, at $24 \mathrm{hr}$ post-injection. Similar changes in EMG activity were found in both muscles, but for clarity of presentation data is shown for just one muscle (as noted) in the figures. Phasic activity resulting from animal movement was excluded from analysis.

Bilateral intracerebral injections were made following the implantation of EMG electrodes to minimize the confounding effects of the anesthetic on EMG activity, and all animals were fully alert by $1 \mathrm{hr}$ post-injection. Thus, while it is possible that EMG activity was reduced in the first hour of recordings because of the residual effects of Nembutal, which we have shown does lower tonic EMG activity (unpublished observations), comparison of the current data with those from previous studies, in which animals were injected after full recovery from anesthesia, suggests these effects are minor (Hemsley and Crocker 1998, 1999a).

Behavioral observations were made throughout the course of EMG recording; however, because of the sensitivity of the EMG signal to disturbance, animals were not handled during the recording period.

\section{Quantitative Autoradiography}

Following the recording of EMG activity, rats were decapitated. Brains were removed, bisected along the sagittal plane, embedded in OCT compound, and snap-frozen in isopentane-quenched liquid nitrogen, then cut 
on a cryostat into $20 \mu \mathrm{m}$ sections that were mounted on gelatin-coated slides. The left hemisphere was used for subsequent assessment of receptor occupancy because it is involved in motor control of the right hindlimb, from which EMG recordings were made. Sections were cut in a sagittal plane to allow assessment of receptor occupancy within the striatum and substantia nigra simultaneously. A method based on that of Schotte et al. (1993) for D2 receptor occupancy was used to determine the occupancy of D2 receptors by the irreversible and reversible antagonists, and a similar method was developed by us to determine D1 receptor occupancy.

Briefly, sections were incubated with either the D1 receptor ligand, $\left[{ }^{3} \mathrm{H}\right] \mathrm{SCH} 23390(3 \mathrm{nM}$, Amersham, Australia) or the D2 receptor ligand [ $\left.{ }^{125} \mathrm{I}\right]$ sulpiride $(0.3 \mathrm{nM}$, Amersham, Australia) for $10 \mathrm{~min}$ at room temperature. Sections were washed $(2 \times 2 \mathrm{~min})$ in ice-cold Tris buffer $(50 \mathrm{mM})$ to stop the reaction, and were air dried before being apposed to tritium-sensitive film (Hyperfilm, Amersham) for 5-7 days (D2) or 3-4 weeks (D1), together with appropriate standards (Amersham, Australia). Autoradiographs were analyzed using a computerized densitometry system (MD20, Flinders Imaging, Flinders University, Australia). Areas of receptor occupancy were identified using this system and optical densities (OD) calculated for the areas. OD values were converted to $\mathrm{nCi} / \mathrm{mg}$ of tissue by reference to ${ }^{3} \mathrm{H}$ or ${ }^{125} \mathrm{I}$ standards (Amersham, Australia), and receptor concentration was calculated from the average optical density of 3-4 sections per rat, after subtraction of non-specific binding.

Schotte et al. (1993) acknowledged that the calculated D2 receptor occupancy using the ex vivo method is likely to be lower than that formed in vivo because of diffusion of drug during the assay. Therefore, pre-incubation washes were not performed, and the incubation time was reduced to $10 \mathrm{~min}$ to limit diffusion of drugreceptor complexes. While D1 receptor occupancy has not been previously determined by other groups to our knowledge, we would predict that some diffusion of SCH23390 will also occur during this assay; therefore, the values obtained may also underestimate in vivo occupancy.

\section{Statistical Analysis}

Parametric statistics (one-way ANOVA with post-hoc Bonferroni's, where appropriate, and multivariate ANOVA with post-hoc Ryan, Einot, Gabriel, and Welsch multiple F-test [REG-WF], and adjustment using Sidak's test for multiple comparisons) were employed to compare EMG activity in drug-treated rats with the EMG activity of the control group for each injection site. A $p$ value of $<.05$ was considered to be statistically significant.

\section{RESULTS}

\section{The Role of Striatal Dopamine Receptors in the Regulation of EMG Activity}

Effect of Irreversible Antagonism of Striatal Dopamine Receptors by EEDQ on EMG Activity. Bilateral injections of EEDQ $(0.5 \mu l)$ into the ventral striatum resulted in significant increases in EMG activity that first reached statistical significance $1 \mathrm{hr}$ post-injection, remained elevated at $5 \mathrm{hr}$ (Figure 1), and were still evident at $24 \mathrm{hr}$ post-injection (see Figure 2). Bilateral injection of a smaller volume of EEDQ $(0.2 \mu \mathrm{l})$ into the ventral striatum also resulted in significant increases in EMG activity from 2-5 hr post-injection. The effects on EMG activity were accompanied by marked cataleptic behavioral changes including akinesia, hunched posture, and splayed limbs.

Bilateral injections of EEDQ $(0.5 \mu l)$ into the dorsal striatum, however, did not significantly increase EMG activity at any time up to $5 \mathrm{~h}$ post-injection (Figure 1). Further, behavioral changes, such as those seen following ventral EEDQ injections, were not observed.

Effect of Preprotection of Dopamine D1 and D2 Receptors on EMG Activity Following EEDQ Injection into the Ventral Striatum. In rats preprotected with both SCH23390 and the selective D2 receptor antagonist raclopride $1 \mathrm{hr}$ before injection of EEDQ $(0.5 \mu \mathrm{l})$ into the ventral striatum, there was no significant change in EMG activity compared with DMSO injected control rats at $24 \mathrm{hr}$ post-injection. The combined raclopride and SCH23390 pre-treatment increased EMG activity for up to $5 \mathrm{hr}$ post-injection in DMSO and EEDQ in-

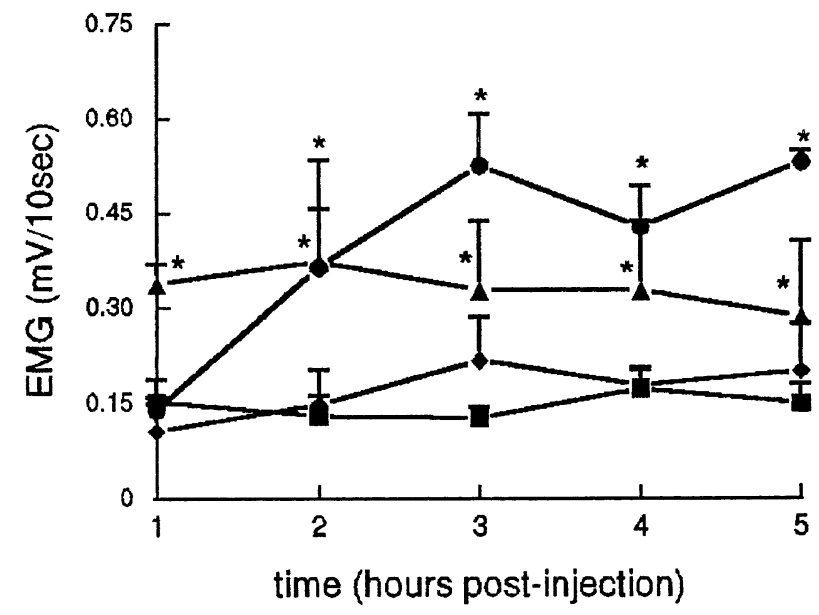

Figure 1. Effect of EEDQ (1M solution) injections into the ventral and dorsal striatum on EMG activity in the gastrocnemius muscle over time. ${ }^{*}=$ significantly different from DMSO control, $p<.05$. $=$ VSTR $0.2 \mu l, \boldsymbol{\Delta}=$ VSTR $0.5 \mu l$, $\bullet=$ DSTR $0.5 \mu \mathrm{l}, \mathbf{\square}=$ Control. Data is mean \pm SEM, $n=$ 4/group. 


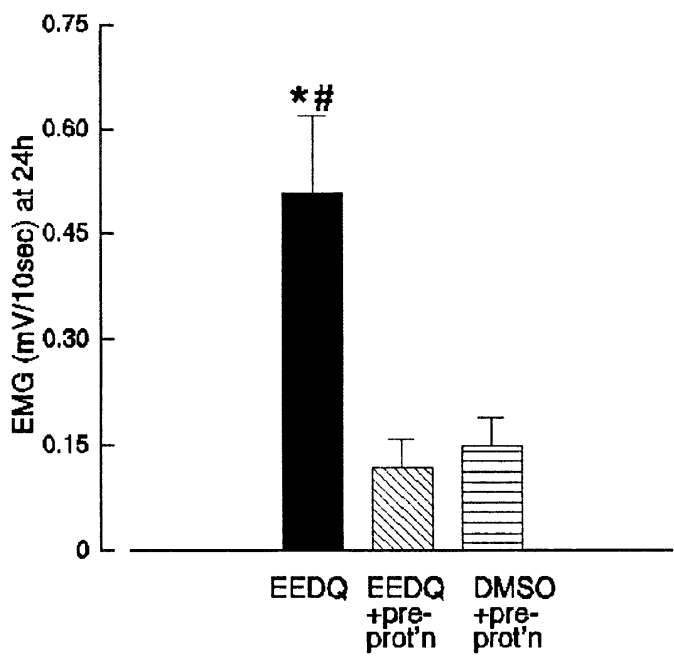

Figure 2. EMG activity in the tibialis muscle at $24 \mathrm{~h}$ following pre-protection of dopamine D1 and D2 receptors by pretreatment with both $\mathrm{SCH} 23390(1.7 \mu \mathrm{mol})$ and raclopride (75 $\mu \mathrm{mol})$ (s.c.) respectively, $1 \mathrm{hr}$ prior to EEDQ injection $(0.5 \mu \mathrm{l}$ of $1 \mu \mathrm{M}$ solution) into the ventral striatum. ${ }^{*}=$ significantly different from DMSO control, $p<.05$, \# = significantly different from EEDQ + pre-protection $p<.05$ Data is mean \pm SEM, $n=2-3$ /group.

jected rats, but no increases were observed in either group at $24 \mathrm{hr}$. However, rats that received the same bilateral injection of EEDQ into the VSTR with no preprotection showed significantly increased EMG activity at $24 \mathrm{hr}(p<.05)$ (Figure 2). These findings confirm that the effects of EEDQ are mediated through dopamine receptor mechanisms.

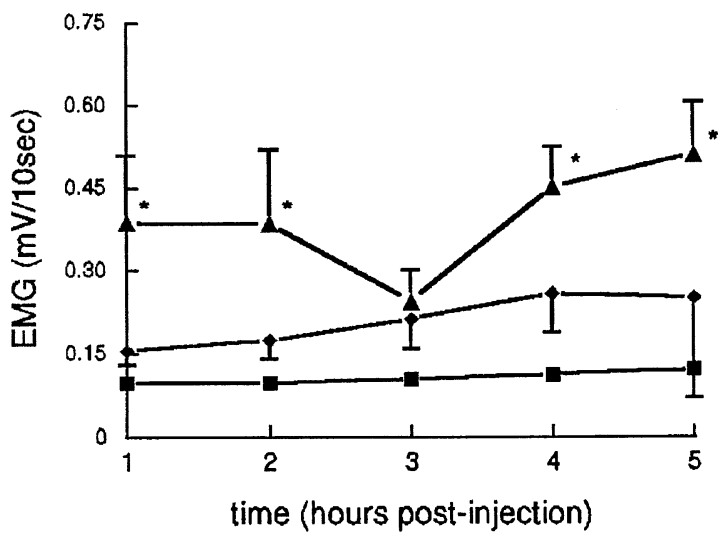

Figure 3. Effect of SCH23390 injected into the ventral and dorsal striatum on EMG activity in the gastrocnemius muscle over time. ${ }^{*}=$ significantly different from saline control $p<.05 . \boldsymbol{\Delta}=$ Ventral striatum $(0.2 \mu \mathrm{l}$ of $20 \mathrm{nM}$ solution $) \bullet=$ Dorsal striatum $(0.5 \mu \mathrm{l}$ of $20 \mathrm{nM}$ solution), $\boldsymbol{\square}=$ Control. Data is mean $\pm \mathrm{SEM}, n=6$ /group.

\section{Effect of Selective, Reversible Antagonism of Striatal Dopamine Receptors on EMG Activity}

Effects of SCH23390. Injection of SCH23390 (0.2 $\mu \mathrm{l}$ of a $20 \mathrm{nM}$ solution) into the ventral region of the striatum produced significant increases in EMG activity for up to $5 \mathrm{hr}$ post-injection (Figure 3), and rats were akinetic and unresponsive, and exhibited a hunched posture, splayed limbs, and rigid tail, and appeared mildly sedated. In contrast, there were no effects on EMG activity of $\mathrm{SCH} 23390(0.5 \mu \mathrm{l}$ of a $20 \mathrm{nM}$ solution $)$ injected into the dorsal striatum at any time point post-injection (Figure 3). Behavioral changes were not observed and the rats were indistinguishable from vehicle-injected controls.

Effects of Sulpiride. Administration of (-)sulpiride $(0.5 \mu \mathrm{l}$ of $30 \mathrm{nM}$ solution) into the ventral striatum resulted in significant increases in EMG activity, from 2-5 hr post-injection (Figure 4), and cataleptic postural and behavioral changes were observed. Injection of sulpiride $(0.5 \mu \mathrm{l}$ of $30 \mathrm{nM}$ solution) into the dorsal striatum, however, had little sustained effect on muscle rigidity or behavior (Figure 4). Thus, although a transient increase in EMG activity was observed at $1 \mathrm{hr}$ post-injection, levels were not significantly different from control values from $2-5 \mathrm{hr}$ post-injection.

\section{Determination of the Striatal Site of D1 and D2 Receptors Mediating Increases in EMG Activity}

Effects of EEDQ Injections on D1 and D2 Dopamine Receptor Occupancy. To determine the effect of intrastriatal injections of EEDQ on the site and extent of dopamine D1 and D2 receptor occupancy in the stria-

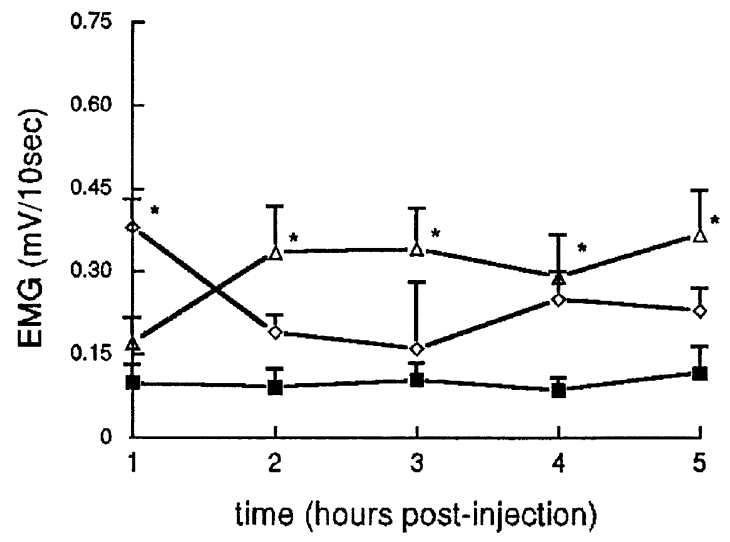

Figure 4. Effect of (-)sulpiride $(0.5 \mu \mathrm{l}$ of $30 \mathrm{nM}$ solution) injected into the ventral and dorsal striatum on EMG activity in the gastrocnemius muscle over time. ${ }^{*}=$ significantly different from saline control, $p<.05$. $\triangle=$ Ventral striatum, $\diamond=$ Dorsal striatum, $\mathbf{\square}=$ Control. Data is mean \pm SEM, $n=$ 6/group. 


\section{DMSO}

a)

D1

c)

D2

e)

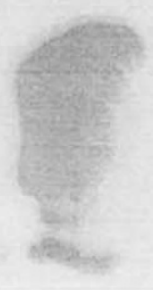

b)

\section{EEDQ}

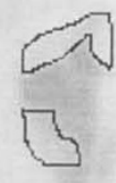

d)

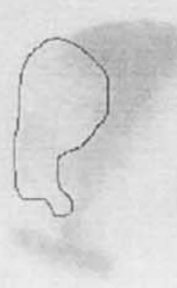

D1

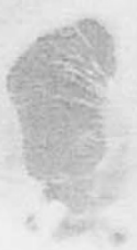

g)

D2 f)

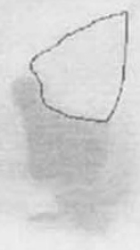

h)

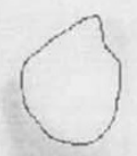

Figure 5. Representative autoradiographs depicting the occupancy of dopamine receptors at $5 \mathrm{hr}$ following intracerebral injections into the VSTR (a-d) and DSTR (e-h). Computer-assisted densitometry was used to assess D1 (a, b, e, f) and D2 (c, $\mathbf{d}, \mathbf{g}, \mathbf{h})$ receptor occupancy in the striatum and substantia nigra following injection of either DMSO (a, c, e, g) or EEDQ (b, d, $\mathbf{f}, \mathbf{h})$. Lines have been drawn around the areas where dopamine receptors are occupied by EEDQ in $\mathbf{b}, \mathbf{d}, \mathbf{f}$, and $\mathbf{h}$.

tum, rats were killed at $5 \mathrm{hr}$ after ventral or dorsal injections and the brains processed for assessment of dopamine receptor occupancy using computer assisted densitometry, as described in Methods.
Figure 5 shows D1 and D2 receptor autoradiographs of sections from a control rat (a and c, respectively) and from rats in which lighter areas of receptor occupancy are clearly visible following injections of EEDQ into the 
a)

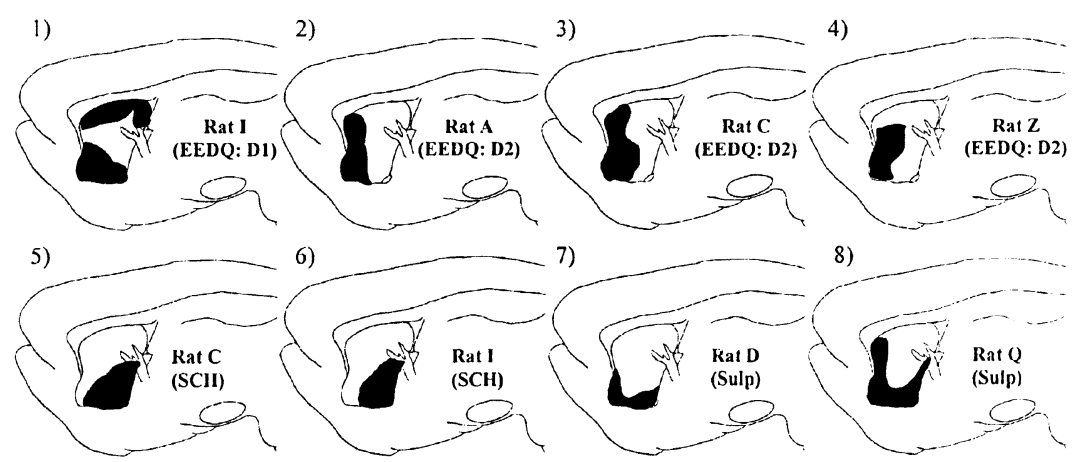

b)

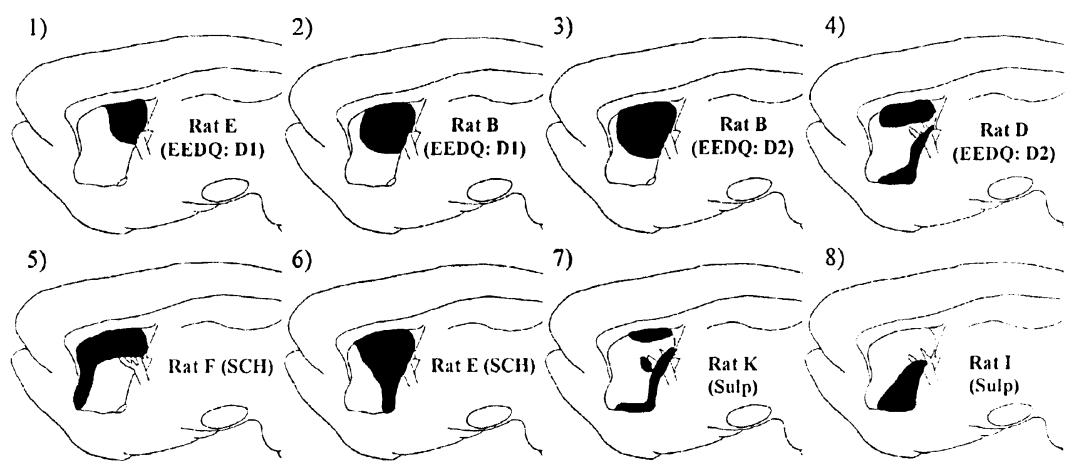

Figure 6. Diagrams of sagittal sections from animals that have received bilateral intracerebral injections of EEDQ, SCH23390, or sulpiride as described in the text. The area of receptor occupancy was determined by computer assisted image analysis of individual autoradiographs and is indicated by the black filled regions. Rat identification, drug injected, and receptor type is indicated. Sections in (a) depict areas of receptor occupancy in rats demonstrating significant increases in EMG activity, and those in (b) depict areas of receptor occupancy in rats that did not demonstrate significant changes in EMG activity. Lateral co-ordinate $2.4 \mathrm{~mm}$ (Paxinos and Watson 1986). ventral striatum ( $b$ and $d$, respectively). The level of receptor occupancy within these areas was assessed by computer-assisted densitometric analysis. The ventral injections resulted in significant increases in EMG activity. Conversely the autoradiographs in Figure $5(\mathrm{e}-\mathrm{h})$ show areas of D1 and D2 receptor occupancy following EEDQ injections into the dorsal striatum ( $\mathrm{f}$ and $\mathrm{h}$ ), which were not associated with increased EMG activity. It can be seen that there was some spread of EEDQ from the injection site, especially into the dorsal striatum, following the ventral injections (Figure 5).

Next, sagittal sections were examined using the computerized image analysis system to assess the site and extent of diffusion of injections, as indicated by areas of receptor occupancy that were significantly different from surrounding areas. The areas of receptor occupancy were copied onto transparent sheets along with appropriate landmarks that could be overlaid on maps in the brain atlas (Paxinos and Watson 1986) using a method first described in Cameron and Crocker (1989). Examples of the location of areas of receptor occupancy associated or not associated with increased EMG activity are shown diagrammatically in Figure 6a (1-4) and $6 \mathrm{~b}(1-4)$, respectively. When the areas of occupancy by EEDQ associated with increased EMG activity were overlapped, a common area of intersection was identified in the ventral striatum (Figure 7a). This "EEDQ site" was then compared with the areas of receptor occupancy by EEDQ in rats that showed no increase in EMG activity. None of these latter sections overlapped with the ventral EEDQ site.

At $5 \mathrm{hr}$ following EEDQ injections, the levels of D1 and D2 receptor occupancy in the EEDQ site were $79.7 \pm$ $7.4 \%$ and $88.9 \pm 7.9 \%$, respectively. There was evidence of some spread of EEDQ to the substantia nigra following striatal injections, with receptor occupancy of $10.8 \pm$ $4.2 \%$ for D1 and $37.8 \pm 14 \%$ for D2 receptors, assessed for the whole nigral area.

Effects of SCH23390 on D1 Dopamine Receptor Occupancy. To determine the site and extent of D1 receptor occupancy associated with increases in EMG activity, sagittal sections were processed for assessment of D1 occupancy following injection of $\mathrm{SCH} 23390(0.2$ or $0.5 \mu \mathrm{l}$ of $20 \mathrm{nM}$ solution) into ventral and dorsal striatal sites, respectively. Examples of the sites of SCH23390 occupancy associated with increased EMG activity after ventral injections are shown diagrammatically in Figure 6a (5\&6), and sites not associated with EMG increases following dorsal injections in Figure $6 \mathrm{~b}$ (5 and 6).

The areas of receptor occupancy by SCH23390 were mapped as described above for EEDQ, and the common area associated with increased EMG activity, was identified (Figure 7b). This ventral "SCH23390 site" 
a)

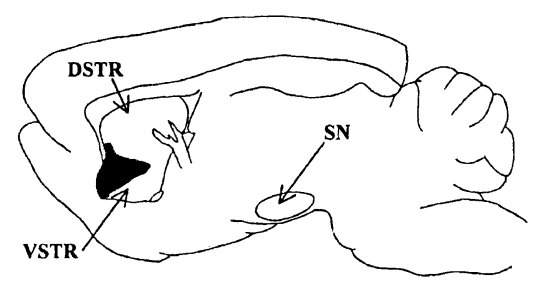

b)

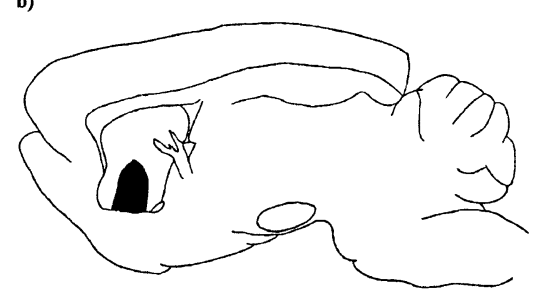

c)

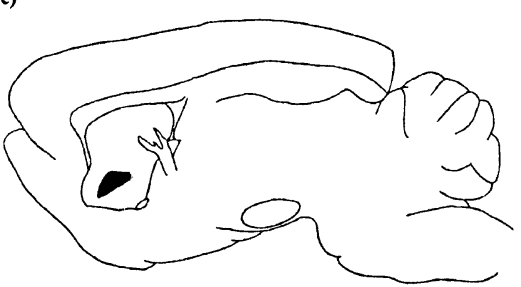

d)

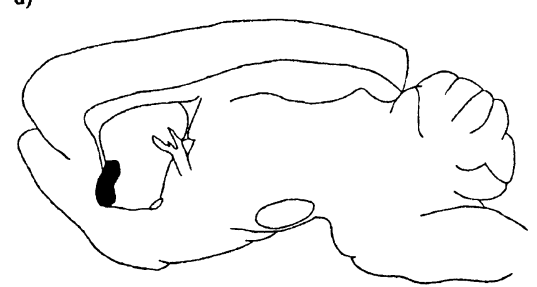

Figure 7. Diagrams of sagittal sections demonstrating the localization of ventral striatal "sites" critical for the production of increased muscle rigidity observed following intracerebral injection of drugs into the ventral striatum. The sites were mapped by incorporating information from rats that did and did not exhibit increases in EMG activity up to $5 \mathrm{hr}$ post-injection. Approximate co-ordinates for the sites are indicated (Paxinos and Watson 1986). (a) "EEDQ site": Number of rats $(n=13)$, number of sections $\left(n_{1}=32\right)$ examined to produce the mapped image. AP: 0.25 to $+2.1 \mathrm{~mm}$, $\mathrm{L} \pm 2.4 \mathrm{~mm}, \mathrm{~V}: 5.4$ to $-7.5 \mathrm{~mm}$. (b) "SCH23390 site": Number of rats $(n=10)$, number of sections $\left(n_{1}=22\right)$ examined to produce the mapped image. AP: 0.2 to $+1.3 \mathrm{~mm}, \mathrm{~L} \pm 2.4$ $\mathrm{mm}, \mathrm{V}: 5.4$ to $-7.5 \mathrm{~mm}$. (c)Area of overlap between the "EEDQ site" (a) and the "SCH23390 site" (b). AP: 0.2 to +1.3 $\mathrm{mm}, \mathrm{L} \pm 2.4 \mathrm{~mm}, \mathrm{~V}: 6.0$ to $-7.5 \mathrm{~mm}$. (d) "Sulpiride site": Number of rats $(n=18)$, number of sections $\left(n_{1}=40\right)$ examined to produce the mapped image. A: +1.0 to $+2.1 \mathrm{~mm}$, $\mathrm{L}: \pm 2.4 \mathrm{~mm}, \mathrm{~V}: 5.5$ to $-7.5 \mathrm{~mm}$.

was compared with the areas occupied following dorsal injections (not associated with EMG increases), which confirmed that there was no overlap of these areas with the site. The level of D1 occupancy in the functionally defined SCH23390 site was $44.2 \pm 11.9 \%$. Following ventral and dorsal striatal injections, D1 receptor occupancy in the substantia nigra was $26.0 \pm 3.1 \%$ and $38.2 \pm$ $7.4 \%$, respectively.

Subsequent overlay of the EEDQ site with the SCH23390 site allowed further definition of the ventral striatal region critical for increases in EMG activity following D1 receptor antagonism-the "D1 site," which is shown in Figure 7c.

Effects of Sulpiride on D2 Dopamine Receptor Occupancy. Sagittal sections were processed for assessment of D2 receptor occupancy following injection of sulpiride $(0.5 \mu \mathrm{l}$ of $30 \mathrm{nM}$ solution) into the ventral and dorsal striatal sites. Figure 6a (7 and 8) shows diagrammatic representations of the areas of D2 receptor occupancy following injection of sulpiride into the ventral striatum that resulted in a significant increase in EMG activity. Conversely, Figure 6b (7 and 8) shows areas of D2 receptor occupancy following sulpiride injection into the dorsal striatum that were not associated with sustained significant increases in EMG activity.

The areas of D2 receptor occupancy were mapped as described previously. The common intersectional area associated with increased EMG activity following sulpiride injections was identified (Figure 7d) and was found to not overlap with areas of occupancy in rats that showed no EMG increases. The D2 receptor occupancy in the functionally defined sulpiride site was $72.3 \pm 12.1 \%$ following $0.5 \mu \mathrm{l}$ of $30 \mathrm{nM}$ sulpiride. The sulpiride site appears to be contained within the EEDQ site (Figure 7a). There was also some spread of sulpiride to the substantia nigra, with nigral D2 occupancies of $28.5 \pm 7.4 \%$ observed following sulpiride injections into the ventral striatum, and $24.5 \pm 14.8 \%$ following dorsal injections.

\section{The Role of Nigral Dopamine Receptors in the Regulation of EMG Activity}

Effects of SCH23390 on EMG Activity and D1 Receptor Occupancy. Intra-nigral injection of SCH23390 (0.5 $\mu$ l of $20 \mathrm{nM}$ solution) produced significant, maximal increase in EMG activity from 1-5 hr in the tibialis and 1-4 hr in the gastrocnemius muscle post-injection (Figure 8). Rats were immobile, cataleptic, and exhibited a hunched posture with splayed limbs and rigid tails. The occupancy of dopamine D1 receptors $5 \mathrm{hr}$ following intra-nigral administration of SCH23390, was $50.9 \pm 8.6 \%$ in the substantia nigra, and $12.3 \pm 6.9 \%$ uniformly distributed throughout the whole striatal area.

Effects of Sulpiride on EMG Activity and D2 Receptor Occupancy. Intra-nigral administration of (-)sulpiride $(0.5 \mu \mathrm{l}$ of $30 \mathrm{nM}$ solution) did not significantly increase EMG activity from baseline levels (Figure 8). 


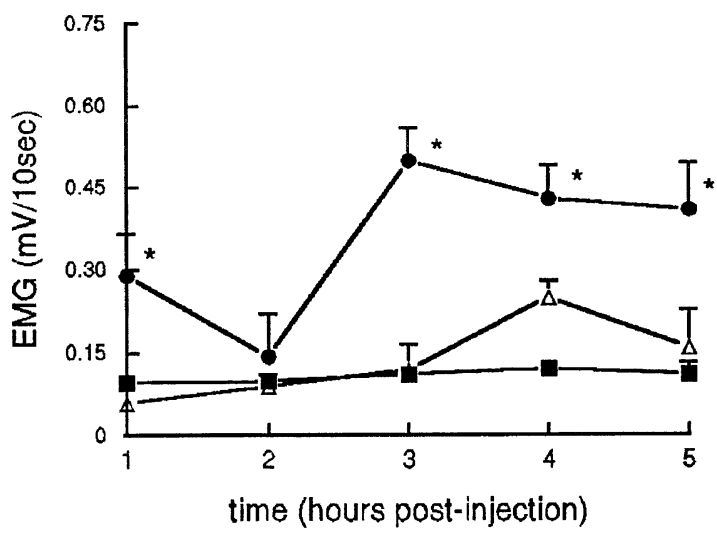

Figure 8. Effect of SCH23390 (0.5 $\mu$ l of $20 \mathrm{nM}$ solution) or (-)sulpiride $(0.5 \mu \mathrm{l}$ of $30 \mathrm{nM}$ solution) injected into the substantia nigra on EMG activity in the gastrocnemius muscle over time. * = significantly different from vehicle control, $p<.05 .-\mathrm{SCH} 23390$ (data for tibialis muscle, $\mathrm{n}=9$ ),$\triangle=$ Sulpiride $(n=6), \mathbf{\square}=$ Control $(n=6)$. Data is mean \pm SEM.

No obvious behavioral effects were noted and animals appeared alert and responsive at all times. Dopamine D2 receptor occupancy at $5 \mathrm{~h}$ post-injection following intranigral sulpiride was $50.0 \pm 19.0 \%$ in the substantia nigra and $21.7 \pm 9.6 \%$ in the striatum.

\section{DISCUSSION}

The current findings provide new information about motor control by demonstrating that antagonism of both D1 and D2 receptors in functionally defined striatal sites play a key role in the regulation of muscle tone. Significantly, they extend observations from both human PET studies (Farde et al. 1992) and our recent animal studies (Hemsley and Crocker 1999a), which focused on the role of D2 receptors by localizing adjacent D1 and D2 sites within the ventral portion of the striatum. In addition, the findings show that dopamine D1 receptors in the substantia nigra play an important role in muscle tone regulation. This information supplements current knowledge about the role of nigral D1 receptor mechanisms, which have been previously implicated only in the expression of dopamine behaviors (LaHoste and Marshall 1990; Yurek and Hipkens 1994; Lee et al. 1995).

The experimental approach used to identify striatal and nigral sites involved the use of the irreversible D1/ D2 antagonist, EEDQ, and reversible selective D1 (SCH23390) and D2 (sulpiride) antagonists. Because EEDQ has been reported to bind irreversibly to a number of neurotransmitter receptors (Battaglia et al. 1986; Belleau et al. 1969; Norman and Creese 1986), other than D1 and D2 receptors, it was necessary to demon- strate that its effects were mediated via dopamine receptors. This was done by comparing the effects of intrastriatal injections of EEDQ alone on EMG activity, with those of EEDQ injections following protection of D1 and D2 receptors by pretreatment with $\mathrm{SCH} 23390$ and raclopride, respectively. Figure 2 shows that in preprotected animals, EEDQ did not increase EMG activity, whilst EMG activity was significantly increased in the group receiving EEDQ without pre-protection.

This finding supports the conclusion that the effects of EEDQ on EMG activity are mediated by dopamine receptors, which is consistent with previous reports about the involvement of dopamine receptors in the effects of EEDQ (Crocker 1995; Hemsley and Crocker 1998). However, the validity of the conclusion depends on the specificity of the compounds used in the preprotection regimen. Raclopride is selective for dopamine D2 and D3 subtypes, and has no other known receptor interactions (Leysen et al. 1993). In addition, although high doses of $\mathrm{SCH} 23390$ have been reported to protect $5 \mathrm{HT}_{2 \mathrm{C}}$ receptors (Meller et al. 1985), the low doses used in the present study selectively protect D1 receptors, because of the 10-fold higher affinity of $\mathrm{SCH} 23390$ for D1 compared with $5 \mathrm{HT}_{2 \mathrm{C}}$ receptors in vivo (Bischoff et al. 1986). Finally, our past studies have demonstrated that antagonism of serotonin receptors does not result in increases in EMG activity (Crocker 1995). Overall this body of evidence supports the view that the effects of EEDQ are mediated via dopamine receptors.

The current findings clearly support a role for D1 receptors in the substantia nigra and ventral striatum in the regulation of EMG activity and cataleptic behavior. These observations are consistent with the observations of other researchers who demonstrated that blockade of D1 receptors following peripheral (Christensen et al. 1984; Meller et al. 1985; Ogren and Fuxe 1988), or intracerebral administration of SCH23390 (Fletcher and Starr 1988; Ossowska et al. 1990) resulted in the production of catalepsy. In addition, in a previous study we showed increased EMG activity was associated with $\sim 70 \%$ inactivation of both D1 and D2 receptor subfamilies in the substantia nigra (Hemsley and Crocker 1998). The current findings suggest that the effect of intranigral injection of EEDQ on muscle tone is solely due to inactivation of nigral D1 receptors because selective antagonism of D1 receptors resulted in increased EMG activity, whereas blockade of D2 receptors had no effect.

In terms of the role of D1 receptors in the ventral striatum and substantia nigra, recent findings have demonstrated that they regulate pilocarpine-induced jaw movements (Mayorga et al. 1999). Further, it has been reported that D1 receptors in these regions are involved in the production of motor behaviors, such as dopamine agonist-induced stereotypy or catalepsy (Arnt 1985; Ossowska et al. 1990; Wardas et al. 1995). In addi- 
tion, two of these studies also demonstrated the lack of involvement of the dorsal striatal region in the production of stereotypy or catalepsy, respectively (Arnt 1985; Ossowska et al. 1990). Because the current results suggest the involvement of ventral striatal and nigral D1 receptors in the regulation of normal muscle tone, it is important that the D1 and D2 antagonistic properties of common antipsychotic drugs, such as chlorpromazine and fluphenazine, are taken into account when the motor side effect potential of these compounds is considered.

The current findings also provide substantial support for the involvement of striatal D2 receptors, particularly those located in the ventral region, in mediating motor side effects such as muscle rigidity, which is frequently observed following antipsychotic drug administration. These results both confirm and extend the findings of other researchers, who have detailed the importance of D2 receptors in the ventral striatum in the regulation of motor behaviors such as catalepsy (Ossowska et al. 1990; Wardas et al. 1995).

An important common finding of previous experimental (Leysen et al. 1993; Hemsley and Crocker 1998; Alcock and Crocker 1999), and clinical studies (Farde et al. 1992; Nordstrom et al. 1995), is that a threshold level of occupancy of striatal D2 receptors is crucial for the production of motor side effects. Previously, we have established that a threshold of approximately $60-70 \%$ D2 receptor occupancy in the striatum needs to be attained before motor side effects become apparent (Hemsley and Crocker 1998, 1999a).

In the current study all estimations of receptor occupancy were performed at $5 \mathrm{hr}$ post-injection, when sustained increases in EMG activity had been observed for at least 2 hours. At $5 \mathrm{hr}$ following ventral striatal injections of the irreversible antagonist EEDQ, D2 receptor occupancy in the ventral site was $89-92 \%$ and exceeded the threshold determined in our earlier studies. The D2 occupancy threshold was also exceeded in the functionally defined sulpiride site, which had an occupancy of $72 \%$ at $5 \mathrm{hr}$ post-injection. However, taking into account findings from other studies, which have investigated D2 occupancy following injection of reversible D2 antagonists (Sumiyoshi et al. 1995; Hemsley and Crocker 1999a), it is likely that peak occupancy occurred from 1-2 hr post injection. Nevertheless, the observation that no sustained increases in EMG activity were seen following injection of either EEDQ or sulpiride into the dorsal striatum, cannot be attributed to sub-threshold D2 occupancy being attained, because $79.5 \pm 5.5 \%$ of $\mathrm{D} 2$ receptors in the dorsal half of the striatum were occupied by EEDQ, and $83.0 \pm 6.1 \%$ of $\mathrm{D} 2$ receptors were occupied by sulpiride at $5 \mathrm{hr}$ post-injection.

Similar considerations apply to comparisons of the occupancy of D1 receptors by EEDQ and SCH23390. The occupancy of dopamine D1 receptors by EEDQ in the ventral striatal D1 receptor site associated with sig- nificant increases in EMG activity was $79.7 \pm 7.4 \%$, whereas that by SCH23390 was $44.2 \pm 11.9 \%$. Again it might be postulated that D1 receptor occupancy by the reversible D1 antagonist SCH23390, was greater at earlier time points, and this level was associated with initiation of increases in muscle rigidity. This view is consistent with findings from a behavioral study (Double and Crocker 1990) in which blockade of dopamine behaviors were associated with greater than $60 \%$ D1 receptor occupancy by EEDQ. Nevertheless, D1 occupancies in the dorsal half of the striatum were $72.9 \pm 12.9 \%$ and $78.7 \pm 9.8 \%$ at $5 \mathrm{hr}$ post-injection following EEDQ and $\mathrm{SCH} 23390$ respectively. These data suggest that the lack of effect on EMG activity of injections of dopamine receptor antagonists into the dorsal region was not because of low occupancy of D1 receptors but more likely because of the fact that these injections did not occupy D1 receptors located in the more ventral region, that are hypothesized to be critical for the maintenance of normal muscle tone-the D1 site.

Another interesting feature of the findings is the fact that significant increases in EMG were observed between 1-2 hr after injection of either the irreversible or reversible antagonists. This time course is consistent with findings from our previous studies, in which the delay appeared to be associated with the time taken for threshold D2 occupancy to be achieved (Hemsley and Crocker 1998, 1999a). However, as rats received intracerebral injections while under anesthesia, it is possible that residual effects of the anesthetic reduced EMG activity up to the $1 \mathrm{~h}$ time point. Nevertheless, the delay is consistent with the maximal cataleptic response observed 90 min after injection of dopamine antagonists (Ogren et al. 1993) and may relate to the timing of post receptor events, such as transcription of immediate early genes (Dragunow et al. 1990).

The present findings are consistent with current theories of how information flow through the basal ganglia is modulated by dopamine. Thus, antagonism of striatal D2 receptors located on medium spiny neurons projecting to the globus pallidus is believed to result in changes in two indirect pathways linking the striatum and substantia nigra, whereas antagonism of D1 receptors on striato-nigral efferents results in inhibition of the direct striato-nigral pathway (DeLong 1990). Overall these changes ultimately lead to reduced excitation of descending motor pathways, and increased muscle tone and akinesia (De Long 1990; Crocker 1997).

We have suggested a possible explanation of the effects of SCH23390 and EEDQ in the substantia nigra (Crocker 1997). It is well accepted that dopamine is released from the dendrites of dopaminergic neurones in the substantia nigra (Cheramy et al. 1981) and can interact with both D2 autoreceptors and with D1 receptors located on the terminals of striato-nigral GABA neurons. It has been reported that when these $\mathrm{D} 1$ receptors 
are stimulated they increase the release of GABA (Flores et al. 1993), so that their blockade by SCH23390 will result in a reduction in GABA release. As a consequence the tonically active nigro-thalamic GABAergic neurons are less inhibited, leading to greater inhibition of the thalamus resulting in inhibition of thalamo-cortical glutamatergic neurones culminating in increased muscle tone and akinesia (DeLong 1990; Crocker 1997).

What the explanations above do not address is our finding that the functionally defined D1 and D2 sites involved in muscle tone regulation are located in two separate, adjacent sites in the ventral, not the dorsal region of the striatum (Figure $7 \mathrm{c}$ and $\mathrm{d}$ ), indicating the striatum is functionally heterogeneous with regard to this regulatory role. The sulpiride site is also close to the D2 site previously defined by us as mediating dopamine agonist-elicited stereotyped head-down sniffing (Cameron and Crocker 1989). Although it has been demonstrated extensively that the striatum is a heterogeneous structure in terms of its neurochemistry (Graybiel and Ragsdale 1978; Graybiel et al. 1979; Herkenham and Pert 1981; Graybiel 1990), functional heterogeneity of this structure has only been documented relatively recently (Cameron and Crocker 1989; Koshikawa et al. 1989; Ossowska et al. 1990; Crocker and Cameron 1992; Wardas et al. 1995). In fact, many clinical and experimental animal studies (including Farde et al. 1992; Leysen et al. 1993) consider the striatum as a homogeneous structure in terms of the actions of dopamine antagonists producing motor side effects.

In the current study, the functionally heterogeneous nature of the striatum is clearly illustrated in the dorsalventral plane. Support for the importance of the ventral striatum in the expression of motor behaviors is provided by several studies (Turski et al. 1984; Arnt 1985; Cameron and Crocker 1989; Ossowska et al. 1990; Crocker and Cameron 1992; Wardas et al. 1995; Alcock and Crocker 1999), which have also shown a distinction between the roles of the dorsal and ventral regions of the striatum. While the dorsal striatum receives considerable neuronal input from cortical motor regions (Kunzle 1975, 1977; Crutcher and DeLong 1984; Alexander and DeLong 1985; McGeorge and Faull 1989; Carelli and West 1991), it is possible that there is crosstalk between the dorsal and ventral regions of the striatum. The ventral region also receives cortical motor inputs (McGeorge and Faull 1989) together with modulatory dopaminergic input from both the substantia nigra and the ventral tegmental area (Beckstead et al. 1979; Hontanilla et al. 1996).

In summary, these data suggest that the regulation of muscle tone is localized in discrete sites within the basal ganglia, with antagonism of dopamine D1 and D2 receptors in the ventral striatum and D1 receptors in the substantia nigra, resulting in increased muscle rigidity. Further, the striatum appears to be functionally hetero- geneous with respect to the control of muscle tone, with antagonism of dopamine D1 and D2 receptors in separate, functionally defined regions of the ventral striatum, but not the dorsal striatum, resulting in increases in EMG activity. It is likely that a threshold of D2 occupancy in the ventral striatum exists, which must be exceeded before increases in muscle rigidity occur, supporting findings from PET studies in humans (Farde et al. 1992). However, further experiments are needed to illuminate the level of D1 and D2 receptor occupancy associated with changes in muscle rigidity in the ventral striatum and substantia nigra. These results shed new light on the respective roles dopamine D1 and D2 receptors in various regions of the basal ganglia play in the regulation of muscle tone, and may aid in the development of new theories to describe the ways in which dopamine regulates muscle tone within basal ganglia structures.

\section{ACKNOWLEDGMENTS}

The financial assistance of the National Health and Medical Research Committee (NMHRC) and the Flinders Medical Centre Foundation is gratefully acknowledged. KMH was a recipient of an NHMRC Biomedical Postgraduate 'Dora Lush' Scholarship.

\section{REFERENCES}

Alcock SJ, Crocker AD (1999): Interactions between striatal acetylcholine and dopamine receptors in motor control. Proc Aust Soc Clin Exp Pharm Toxicol 6:117

Alexander GE, DeLong MR (1985): Microstimulation of the primate neostriatum. II. Somatotopic organization of striatal microexcitable zones and their relation to neuronal response properties. J Neurophysiol 53:1417-1430

Arnt J (1985): Antistereotypic effects of dopamine D-1 and D-2 antagonists after intrastriatal injection in rats. Pharmacological and regional specificity. Naunyn-Schmiedeberg's Arch Pharmacol 330:97-104

Baldessarini RJ, Tarsy D (1980): Dopamine and the pathophysiology of dyskinesias induced by antipsychotic drugs. Ann Rev Neurosci 3:23-41

Battaglia G, Norman AB, Newton PL, Creese I (1986): In vitro and in vivo irreversible blockade of cortical S2 serotonin receptors by N-ethoxycarbonyl-2-ethoxy-1,2dihydroquinoline: a technique for investigating S2 serotonin receptor recovery. J Neurochem 46:589-593

Beckstead RM, Domesick VB, Nauta WJH (1979): Efferent connections of the substantia nigra and ventral tegmental area in the rat. Brain Res 175:191-217

Belleau B, DiTullio V, Godin D (1969): The mechanism of irreversible adrenergic blockade by $\mathrm{N}$-carbethoxydihydroquinolines-model studies with typical serine hydrolases. Biochem Pharmacol 18:1039-1044 
Bischoff S, Heinrich M, Sonntag J-M, Krauss J (1986): The D-1 dopamine receptor antagonist SCH23390 also interacts potently with brain serotonin (5-HT2) receptors. Eur J Pharmacol 129:367-370

Cameron DL, Crocker AD (1989): Localization of striatal dopamine receptor function by central injection of an irreversible receptor antagonist. Neuroscience 32:769778

Carelli RM, West MO (1991): Representation of the body by single neurons in the dorsal striatum of the awake, unrestrained rat. J Comp Neurol, 309:231-249

Casey DE (1989): Clozapine: Neuroleptic-induced EPS and tardive dyskinesia. Psychopharmacol Berl 99:S47-53

Cheramy A, Leviel V, Glowiniski J (1981): Dendritic release of dopamine in the substantia nigra. Nature 289:537542

Chiodo LA, Bunney BS (1983): Typical and atypical neuroleptics: Differential effects of chronic administration on the activity of A9 and A10 midbrain dopaminergic neurons. J Neurosci 3:1607-1619

Christensen AV, Arnt J, Hyttel J, Larsen J-J, Svendsen O (1984): Pharmacological effects of a specific dopamine D-1 antagonist SCH 23390 in comparison with neuroleptics. Life Sci 34:1529-1540

Claghorn J, Honigfield G, Abuzzahab FS Sr, Wang R, Steinbook R, Tuason V, Klerman G (1987): The risks and benefits of clozapine versus chlorpromazine. J Clin Psychopharmacol 7:377-384

Cohen LG, Hallett M (1988): Non-invasive mapping of human motor cortex. Neurology 38:904-909

Cospito JA, Kultas-Ilinsky K (1981): Synaptic organisation of motor corticostriatal projections in the rat. Exp Neurol 72:257-266

Creese I (1983): Classical and atypical antipsychotic drugs: New insights. TINS 6:479-481

Creese I, Burt DR, Snyder SH (1976): Dopamine receptor binding predicts clinical and pharmacological potencies of antipsychotic drugs. Science 192:481-483

Crocker AD (1995): A new view of the role of dopamine receptors in the regulation of muscle tone. Clin Exp Pharmacol Physiol 22:846-850

Crocker AD (1997): The regulation of motor control: An evaluation of the role of dopamine receptors in the substantia nigra. Rev Neurosci 8:55-76

Crocker AD, Cameron DL (1992): Localisation of striatal muscarinic receptors involved in dopamine receptormediated behavioural responses. Neurosci Letts 142: 73-76

Crutcher MD, DeLong MR (1984): Single cell studies of the primate putamen. I. Functional organization. Exp Brain Res 53:233-243

DeLong MR (1990): Primate model of movement disorders of basal ganglia origin. TINS 13:281-285

Donoghue JP, Herkenham M (1986): Neostriatal projections from individual cortical fields conform to histochemically distinct striatal compartments in the rat. Brain Res 365:397-403

Double KL, Crocker AD (1990.): Effects of inactivation of D1 dopamine receptors on stereotypic and thermic responses to quinpirole (LY171555). Neurosci Letts 115:81-85

Double KL, Crocker AD (1993): Quantitative electromyographic changes following modification of central dopaminergic transmission. Brain Res 604:342-344

Double KL, Crocker AD (1995): Dopamine receptors in the substantia nigra are involved in the regulation of muscle tone. Proc Natl Acad Sci USA 92:1669-1673.

Dragunow M, Robertson GS, Faull RLM, Robertson HA, Jansen K (1990): D2 dopamine receptor antagonists induce fos and related proteins in rat striatal neurons. Neuroscience 37:287-294

Farde L, Nordstrom A-L, Wiesel F-A, Pauli S, Halldin C, Sedvall G (1992): Positron emission tomographic analysis of central D1 and D2 dopamine receptor occupancy in patients treated with classical neuroleptics and clozapine. Relation to extrapyramidal side effects. Arch Gen Psychiatry 49:538-544

Fletcher GH, Starr MS (1988): Intracerebral SCH 23390 and catalepsy in the rat. Eur J Pharmacol 149:175-178

Flores G, Valencia J, Rosales MG, Sierra A, Aceves J (1993): Appearance of EMG activity and motor asymmetry after unilateral lesions of the dopaminergic innervation to the subthalamic nucleus in the rat. Neurosci Letts 162:153-156

Graybiel AM (1990): Neurotransmitters and neuromodulators in the basal ganglia. TINS 13:244-253

Graybiel AM, Ragsdale CW (1978): Histochemically distinct compartments in the striatum of human, monkey and cat demonstrated by acetylthiocholinesterase staining. Proc Natl Acad Sci USA 75:5723-5726

Graybiel AM, Ragsdale CW, Moon Edley S (1979): Compartments in the striatum of the cat observed by retorgrade cell labeling. Exp Brain Res 34:189-195

Hacksell U, Jackson DM, Mohell N (1995): Does the dopamine receptor subtype selectivity of antipsychotic agents provide useful leads for the development of novel therapeutic agents? Pharmacol Toxicol 76:320-324

Hemsley KM, Crocker AD (1998): The effects of an irreversible dopamine receptor antagonist, N-ethoxycarbonyl2-ethoxy-1,2-dihydroquinoline (EEDQ), on the regulation of muscle tone in the rat: the role of the substantia nigra. Neurosci Letts 251:77-80

Hemsley KM, Crocker AD (1999a): Raclopride and chlorpromazine, but not clozapine, increase muscle rigidity in the rat: Relationship with D2 dopamine receptor occupancy. Neuropsychopharmacol 21:101-109

Hemsley KM, Crocker AD (1999b): In which regions of the brain does dopamine regulate the control of muscle tone? Proceedings of the Aust Soc Clin Exp Pharmacol Toxicol 6:71

Herkenham M, Pert CB (1981): Mosaic distribution of opiate receptors, parafascicular projections and acetylcholinesterase in rat striatum. Nature 291:415-417

Hoge SK, Appelbaum P, Lawlor T, Beck JC, Litman R, Greer A, Gutheil TG, Kaplan E (1990): A prospective multicenter study of patients' refusal of antipsychotic drugs. J Clin Psych 55:29-35

Hontanilla B, De Las Heras S, Gimenez-Amaya JM (1996): A topographic re-evaluation of the nigrostriatal projec- 
tions to the caudate nucleus in the cat with multiple retrograde tracers. Neuroscience 72:485-503

Karlsson P, Smith L, Farde L, Harnryd C, Sedvall G, Wiesel F-A (1995): Lack of apparent antipsychotic effects of D1 dopamine receptor antagonist SCH39166 in acutely ill schizophrenic patients. Psychopharmacol Berl 121:309-316

Kelley AE, Domesick VB, Nauta WJ (1982): The amygdalostriatal projection in the rat - an anatomical study by anterograde and retrograde tracing methods. Neuroscience 7:615-630

Koshikawa N, Aoki S, Hiruta M, Tomiyama K, Kobayashi M, Tsuboi Y, Iwata K, Sumino R, Stephenson JD (1989): Effects of intrastriatal injections of selective dopamine D-1 and D-2 agonists and antagonists on jaw movements of rats. Eur J Pharmacol 163:227-236

Kunzle H (1975): Bilateral projections from precentral motor cortex to the putamen and other parts of the basal ganglia An autoradiographic study in Macaca fascicularis. Brain Res 88:195-209

Kunzle H (1977): Projections from the primary somatosensory cortex to basal ganglia and thalamus in the monkey. Exp Brain Res 30:481-492

LaHoste G, Marshall JF (1990): Nigral D1 and striatal D2 receptors mediate the behavioural effects of dopamine agonists. Behav Brain Res 38:233-242

Lee CY, Double KL, Crocker AD (1995): Expression of stereotyped behaviour requires stimulation of nigral D1 dopamine receptors. Brain Res 681:205-208

Leysen JE, Janssen PMF, Schotte A, Luyten WHML, Megens AAHP (1993): Interaction of antipsychotic drugs with neurotransmitter receptor sites in vitro and in vivo in relation to pharmacological and clinical effects: role of 5HT2 receptors. Psychopharmacol Berl 112:S40-S54

Mayorga AJ, Trevitt JT, Conlan A, Gianutsos G, Salamone JD (1999): Striatal and nigral D1 mechanisms involved in the antiparkinsonian effects of SKF 82958 (APB): Studies of tremulous jaw movements in rats. Psychopharmacol 143:72-81

McGeorge AJ, Faull RLM (1989): The organisation of the projection from the cerebral cortex to the striatum in the rat. Neuroscience 29:503-537

Meller E, Kuga S, Friedhoff AJ, Goldstein M (1985): Selective $\mathrm{D}_{2}$ dopamine receptor agonists prevent catalepsy induced by SCH 23390, a selective $D_{1}$ antagonist. Life Sci 36: 1857-1866

Nordstrom A-L, Farde L, Nyberg S, Karlsson P, Halldin C, Sedvall G (1995): D1, D2 and 5-HT2 receptor occupancy in relation to clozapine serum concentration: a PET study of schizophrenic patients. Am J Psychiatry 152: 1444-1449

Norman AB, Creese I (1986): Effects of in vivo and in vitro treatments with N-ethoxycarbonyl-2-ethoxy-1,2-dihydroquinoline on putative muscarinic receptor subtypes in rat brain. Molec Pharmacol 30:96-103

Ogren SO, Fuxe K (1988): $\mathrm{D}_{1^{-}}$and $\mathrm{D}_{2}$-receptor antagonists induce catalepsy via different efferent striatal pathways. Neurosci Letts 85:333-338

Ogren SO, Lundstrom J, Nilsson LB (1993): Concentrations of remoxipride and its phenolic metabolites in rat brain and plasma. Relationship to extrapyramidal side effects and atypical antipsychotic profile. J Neural Transm (Gen Sect) 94:199-216.

Ogren SO, Rosen L, Fuxe K (1994): The dopamine D2 antagonist remoxipride acts in vivo on a subpopulation of dopamine D2 receptors. Neuroscience 61:269-283

Ossowska K, Karcz M, Wardas J, Wolfarth S (1990): Striatal and nucleus accumbens $D_{1} / D_{2}$ dopamine receptors in neuroleptic catalepsy. Eur J Pharmacol 182:327-334

Paxinos G, Watson C (1986): The Rat Brain in Stereotaxic Coordinates (2nd ed.). Sydney, Academic Press

Peroutka SJ, Snyder SH (1980): Relationship of neuroleptic drug effects at brain dopamine, serotonin, $\alpha$-adrenergic and histamine receptors to clinical potency. Am J Psychiatry 127:1518-1522

Scherer J, Tatsch K, Schwarz J, Oertel WH, Konjarczyk M, Albus M (1994): D2 dopamine receptor occupancy differs between patients with and without extrapyramidal side effects. Acta Psychiatr Scand 90:266-268

Schotte A, Janssen PFM, Megans AAHP, Leysen JE (1993): Occupancy of central neurotransmitter receptors by risperidone, clozapine and haloperidol, measured ex vivo by quantitative autoradiography. Brain Res 631:191-202

Sedvall G, Farde L, Hall H, Halldin C, Karlsson P, Nordstrom AL, Nyberg S, Pauli S (1995): Utilization of radioligands in schizophrenia research. Clin Neurosci 3:112121

Seeman P, Lee T, Chau Wong M, Wong K (1976): Antipsychotic doses and neuroleptic/dopamine receptors. Nature 261:717-718

Sumiyoshi T, Suzuki K, Sakamoto H, Yamaguchi N, Mori H, Shiba D, Yokogawa K (1995): Atypicality of several antipsychotics on the basis of in vivo dopamine-D2 and serotonin-5HT2 receptor occupancy. Neuropsychopharmacol 12:57-64.

Turski L, Havemann U, Kuschinsky K (1984): GABAergic mechanisms in mediating muscular rigidity, catalepsy and postural asymmentry in rats: Differences between dorsal and ventral striatum. Brain Res 322:49-57

Wardas J, Pietraszek M, Ossowska K, Wolfarth S (1995): Specific involvement of striatal D1 and D2 dopamine receptors in the neuroleptic catalepsy in rats. Pol J Pharmacol 47:349-53

Webster KE (1961): Cortico-striate interraelations in the albino rat. J Anat 95:532-544

Wise SP, Jones EG (1977): Somatotopic and columnar organization in the corticotectal projection of the rat somatic sensory cortex. Brain Res 133:233-235

Yurek DM, Hipkens SB (1994): Intranigral injections of SCH 23390 inhibit SKF 82958-induced rotational behaviour. Brain Res 639:329-32 